\title{
Facile Synthesis of Silver Nanoparticles with High Antibacterial Activity
}

\author{
Anni Feng, Jiankang Cao, Junying Wei, Feng Chang, Yang Yang *(D) and Zongyuan Xiao* \\ Department of Chemical and Biochemical Engineering, College of Chemistry and Chemical Engineering, \\ Pen-Tung Sah Institute of Micro-Nano Science and Technology, Xiamen University, Xiamen 361005, China; \\ 5anne5@sina.com (A.F.); 20620161151564@stu.xmu.edu.cn (J.C.); grace_junying@163.com (J.W.); \\ changwei345@icloud.com (F.C.) \\ * Correspondence: yangyang@xmu.edu.cn (Y.Y.); xiaozy@xmu.edu.cn (Z.X.)
}

Received: 22 October 2018; Accepted: 6 December 2018; Published: 8 December 2018

\begin{abstract}
We report on a reverse microemulsion method for the synthesis of silver nanocrystals and examine their antibacterial activities. As the molar ratio of water to sodium bis(2-ethylhexyl) sulfosuccinate (AOT) increases to 25, a morphology transition from a sphere-like nanocrystal to a wire-like one was observed. For both the gram-negative and gram-positive bacteria, the wire-like silver nanocrystal showed higher antibacterial activities. We conclude that the morphology of silver nanocrystals dominates their antibacterial activity.
\end{abstract}

Keywords: microemulsion; silver nanoparticle; silver nanowire; antibacterial activity

\section{Introduction}

The design, synthesis, and study of new antibacterial materials are of great significance in both materials' chemistry and public health. Since the 1990s, metal nanocrystals have emerged as promising materials as they have vast applications in catalysis [1-6], trace detection [7-11], electronics [12-16], and biomaterials [17-22]. Among the metal nanocrystals, silver nanocrystals have attracted much interest in recent years due to their antibacterial activities [23-32], and they have been widely used in various consumer products such as textiles, food storage containers, laundry additives, paints, and food supplements [33-42]. A large number of methods for fabricating silver nanocrystals have been developed, including chemical reduction [43-48], electrochemical reduction [49-53], template method [54,55], photocatalytic reduction [56-58], break junction [59], and biochemical reduction [60-65].

In the present work, a simple, economic, and effective approach has been developed to prepare silver nanocrystals on the basis of the reverse microemulsion method. In a microemulsion solution containing n-heptane, sodium bis(2-ethylhexyl) sulfosuccinate (AOT), and silver nitrate, silver cations were reduced to silver nanocrystals through the addition of an ascorbic acid solution. The as-prepared silver nanocrystals were characterized thoroughly by scanning electron microscopy (SEM), dynamic light scattering (DLS), and ultraviolet-visible spectroscopy (UV-vis), where a morphological transition from sphere to wire was observed. Their disinfection efficiency was investigated in detail via measurement of the minimum inhibitory concentration (MIC) and the minimum bactericidal concentration (MBC). 


\section{Experimental Details}

\subsection{Reagents}

AOT $(>96 \%)$, ascorbic acid $(>99.7 \%)$, and silver nitrate $(>99.8 \%)$ were purchased from China Medicine (Group) Shanghai Chemical Reagent Corp. (Shanghai, China). AOT was purified according to the previous report [66]. All the other reagents and chemicals were of analytical grade and used as received.

\subsection{Characterization of Silver Nanocrystals}

UV-Vis spectra were recorded with a UV-2010 UV-vis spectrophotometer (Hitachi, Tokyo, Japan) to find the optimized mass fractions of $\mathrm{AOT}\left(\mathrm{W}_{\mathrm{AOT}}\right)$, and to confirm the formation of silver nanocrystals. Scanning electron microscope (SEM) images were collected by a Hitachi S-4800 electron microscope (Tokyo, Japan) after the samples were dropped on to silicon wafers. The powdered samples were subjected to X-ray diffraction (XRD) studies on an X'pert PRO XRD (Malvern Panalytical, Malvern, UK) to identify their structures. The diameter of the synthesized silver nanocrystals was probed by dynamic light scattering (DLS) with a Brookhaven 90 Plus (Brookhaven Instruments Corp., New York, NY, USA) in an ethanol solvent.

\subsection{Synthesis of Silver Nanocrystals}

Figure 1 describes the process of fabrication of our silver nanocrystals. For a typical synthesis (take the sphere-like silver nanoparticles (Ag NP) with a size of around $20 \mathrm{~nm}$ as an example), $0.70 \mathrm{~g}$ AOT was suspended in $50 \mathrm{~mL}$ of $\mathrm{n}$-heptane in a conical flask to form a mixture duplicate with the mass fraction of AOT $\left(\mathrm{W}_{\mathrm{AOT}}\right)=2 \%$, which is realized by using a magnetic stirrer for $30 \mathrm{~min}$. Next, $0.14 \mathrm{~mL}$ of silver nitrate solution $(0.1 \mathrm{~mol} / \mathrm{L})$ was added into one of the two flasks, while $0.14 \mathrm{~mL}$ of ascorbic acid solution $(0.3 \mathrm{~mol} / \mathrm{L})$ was added into the other flask. After 20 min stirring, two types of microemulsion solutions were formed. The microemulsion solution of ascorbic acid was then slowly added into the silver nitrate solution within $10 \mathrm{~min}$. The entire solution was kept stirring for $3 \mathrm{~h}$ at ambient conditions to promote the reaction. The product was centrifuged at $8000 \mathrm{rpm}$ for $10 \mathrm{~min}$ to gather the silver nanocrystals. After being washed with ethanol 3-5 times, the silver nanocrystals were cleaned (Figure S1) and stored in pure ethanol.

\subsection{Characterization of Antibacterial Activity}

The antibacterial activities of silver nanocrystals were investigated by MIC and MBC tests against Escherichia coli (E. coli) and Staphylococcus aureus (S. aureus). The fresh colonies were taken from an agar plate and inoculated into a $10 \mathrm{~mL}$ liquid Luria-Bertani (LB) broth media. Then, $0.1 \mu \mathrm{L}$ of suspended bacteria $\left(10^{8} \mathrm{CFU} / \mathrm{mL}\right)$ were inoculated into a $10 \mathrm{~mL}$ liquid LB media supplemented with 4096,2048 , $1024,512,256,128,64,32,16,8,4,2,1,0.5,0.25$ and $0.125 \mu \mathrm{g} / \mathrm{mL}$ of silver nanocrystals. These samples with gradient concentrations were obtained by the double dilution method (see Supplementary Material for the detailed experimental process), and the silver nanocrystals were stable enough in liquid LB media for antibacterial measurements (Figure S2). A control experiment was performed using broth without silver nanocrystals. The samples were incubated at $37^{\circ} \mathrm{C}$ and stirred at $200 \mathrm{rpm}$ for $24 \mathrm{~h}$. Growth rate was determined by measuring optical density (OD) at $600 \mathrm{~nm}$ at regular intervals. Evaluation of the MIC was done by visual inspection of growth/no-growth in mixtures containing different concentrations of the silver nanoparticles. Further, $100 \mu \mathrm{L}$ of suspension were taken out from the tubes without visible bacteria growth and spread onto agar plates. The plates were then incubated at $37^{\circ} \mathrm{C}$ for $24 \mathrm{~h}$ before the subsequent MBC measurements. The experimental details of MIC and MBC determination, as well as measurement of growth curves, are shown in Appendix A. 


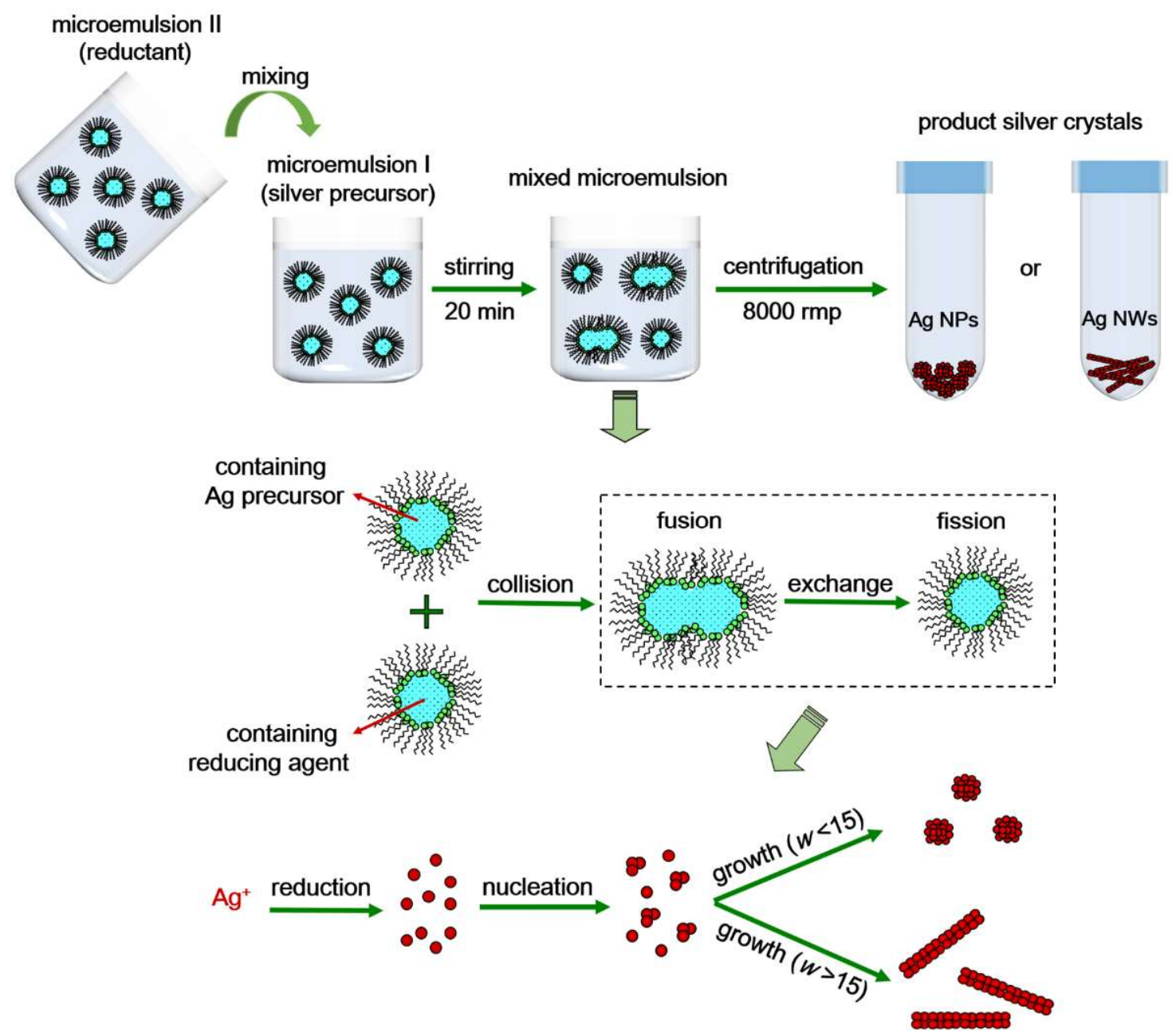

Figure 1. Schematic of the reaction process with a reverse microemulsion method.

\section{Results}

In the fabrication process, liquid media with nanosized water droplets were dispersed in the continuous oil phase (heptane) and stabilized by surfactant AOT molecules at water/oil interface. After mixing the two microemulsions, the water droplets collided with each other and there was an exchange of reactants. The liquid droplets then witnessed the nucleation reaction and growth of the silver nanocrystals. When the size of the as-prepared nanocrystal increased to be comparable with that of the liquid droplet, AOT molecules adsorbed onto the nanocrystals surface to prevent them from aggregating. Mass fraction of surfactant is a key parameter in the synthesis of nanocrystals by the reverse microemulsion method [67]. Surfactant is a necessary condition for nucleation during the synthesis. Nevertheless, excessive surfactants reduce the exchange of solute molecules between micelles, which leads to a lower yield. In order to find the optimized mass fractions of AOT ( $\left.\mathrm{W}_{\mathrm{AOT}}\right)$, we first carried out the UV-vis analysis of the nanocrystal products under different values of $\mathrm{W}_{\mathrm{AOT}}$ and found that the critical value of $\mathrm{W}_{\mathrm{AOT}}$ is between $1 \%$ and $3 \%$. As shown in Figure $2 \mathrm{a}$, the height of the peak increases as $\mathrm{W}_{\mathrm{AOT}}$ increases from $1 \%$ to $2 \%$, while the peak decreases in height as $\mathrm{W}_{\mathrm{AOT}}$ increases further from $2 \%$ to $3 \%$. Moreover, among the three curves, the peak in the $2 \% \mathrm{~W}_{\mathrm{AOT}}$ curve has the smallest value of peak width at half-height (HWHM), indicating that the size distribution is more uniform than others. Thus, in subsequent experiments we adopted the $2 \% \mathrm{~W}_{\mathrm{AOT}}$ as the condition for synthesis.

In the microemulsion method, the size and morphology of the as-prepared nanocrystals can be controlled by the microreactors, i.e., the microemulsion droplets. Thus, we further investigated the 
influence of the molar ratio of water to AOT $(w)$ on the synthesis of nanocrystals by UV-vis analysis in ethanol, as shown in Figure 2b,c. As the molar ratio increases from 3 to 15, the profiles of the adsorption peaks remain the same, while the peak height increases continuously. Notably, as the molar ratio increases further to 25 , the profile of the UV-vis curve evolves to be a double peak, which indicates there is a transition in the morphology of the nanocrystal products.
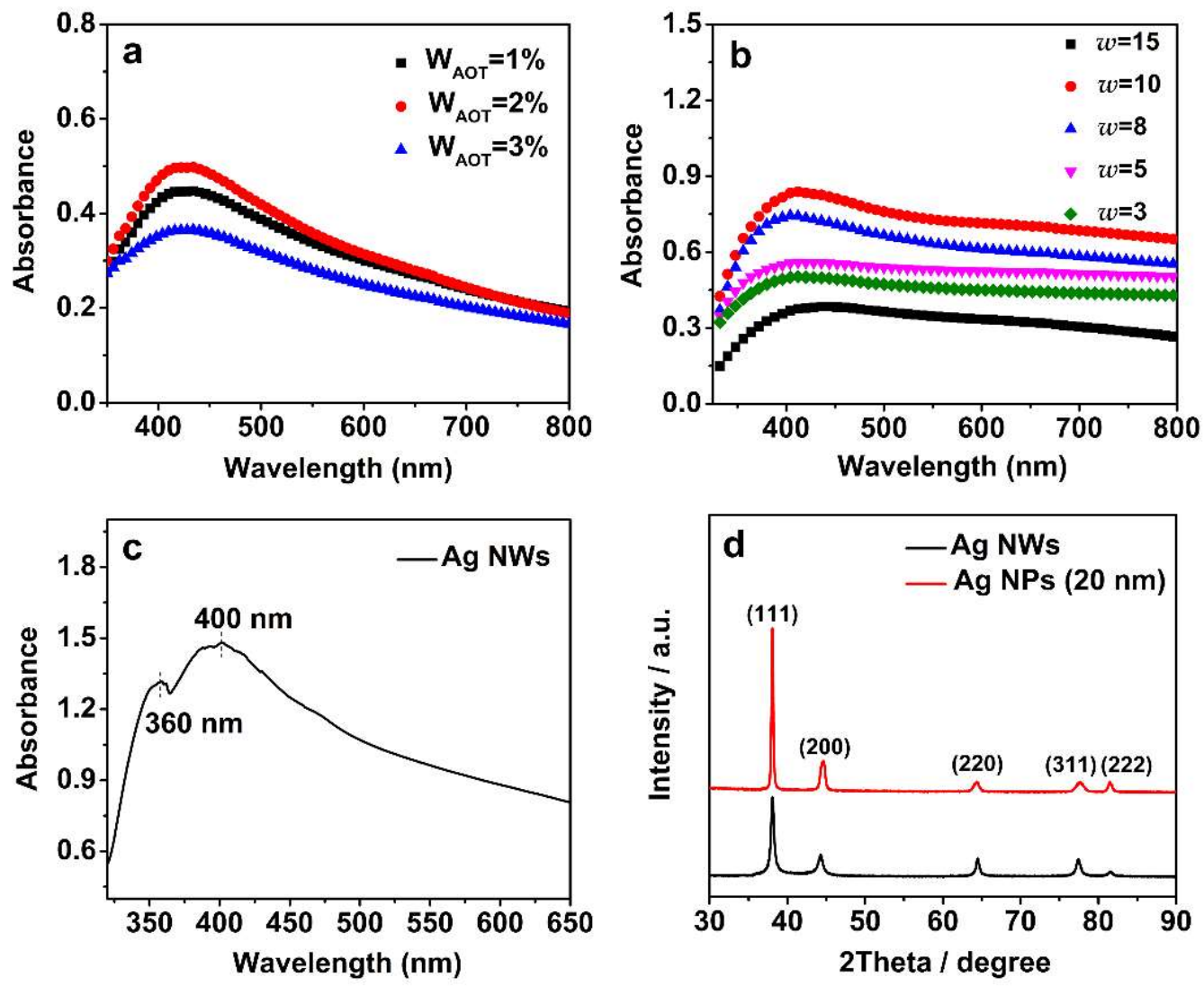

Figure 2. (a) Ultraviolet-visible spectroscopy (UV-vis) spectra of silver nanoparticles with different sodium bis(2-ethylhexyl) sulfosuccinate (AOT) mass fractions. UV-vis spectra of (b) spherical-like silver nanoparticles (Ag NP) synthesized at $w=15,10,8,5$, and 3 and (c) silver nanowires (Ag NW) synthesized at $w=25$. (d) X-ray diffraction (XRD) of spherical-like Ag NP and Ag NW.

To study the transition of the morphology, the nanocrystals were determined by SEM, as shown in Figure 3. It is found that there is a transition from the sphere-like nanocrystal to the wire-like one as the molar ratio of water to AOT increases. With a small ratio, sphere-like silver nanoparticles (Ag NP) were formed, and the favorable diameter of Ag NP increases from $20 \mathrm{~nm}$ to $70 \mathrm{~nm}$ as the ratio $(w)$ increases from 3 to 15 . When the ratio $(w)$ reaches 25 , the assembly of these reagents forms silver nanowires (Ag NW) with a dimeter around $125 \mathrm{~nm}$. The double peaks in Figure 2c can be ascribed to the Ag NW, which is in agreement with a previous report in Reference [68]. We then employed XRD analysis to identify the crystallographic structure and crystallinity of the silver nanocrystal products, as shown in Figure 2d. All diffraction peaks can be ascribed to face-centered cubic silver (JCPDS Card, No. 087-0597). Furthermore, there are no other peaks in the XRD spectra, indicating that our method is capable of preparing silver nanocrystals with high purity. Conventionally, there are two alternative products in the synthesis of nanocrystal: A spherical nanoparticle when a low surfactant concentration is adopted, or a non-spherical nanocrystal when a high surfactant concentration is adopted [69-71]. In this work, although we utilized a low surfactant concentration system, the size and the morphology of silver nanocrystals could be tuned conveniently by adjusting the ratio $(w)$. 

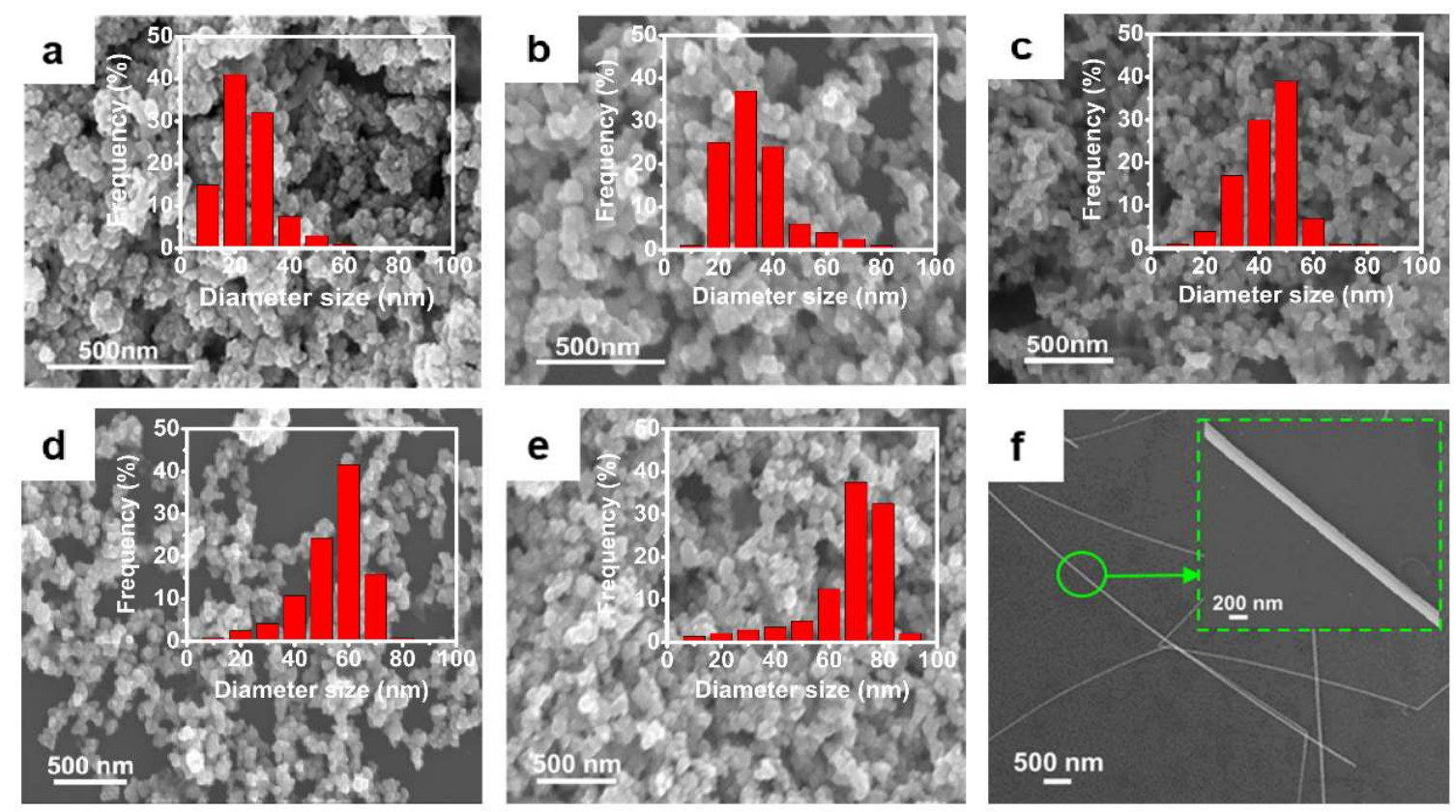

Figure 3. (a-e) Scanning electron microscopy (SEM) images of the Ag NP that synthesized at $w=3,5$, 8,10 and 15, respectively. The inserts show the size distributions, which were measured by dynamic light scattering (DLS) in ethanol based on intensity and had been normalized to a frequency of size distribution. (f) SEM image of the Ag NW that synthesized at $w=25$. In all six experiments, the mass fractions of $\mathrm{AOT}$ are $2 \%$.

The antibacterial activities of the silver nanocrystal products against the E. coli and S. aureus were first evaluated through measurements of MIC and MBC, as shown in Table 1. As the starting molar ratio of water to AOT increases from 3 to 15, the silver nanocrystal products are sphere-like, i.e., Ag NP. It was found that the MIC and MBC values of the $20 \mathrm{~nm} \mathrm{Ag} \mathrm{NP}$ are lower than that of the $50 \mathrm{~nm}$ ones, indicating that the antibacterial activity of silver nanocrystal products decreases as the starting molar ratio increases. Nevertheless, as the molar ratio increases further to 25, the morphology transition of silver nanocrystal products occurs, and the MIC and MBC values against the two strains become lower than that of the $20 \mathrm{~nm}$ Ag NP.

Table 1. The minimum inhibitory concentration (MIC) and minimum bactericidal concentration (MBC) values of the as-prepared nanocrystal products.

\begin{tabular}{ccccccc}
\hline \multirow{2}{*}{ Bacteria } & \multicolumn{3}{c}{ MIC $(\mu \mathrm{g} / \mathbf{m L})$} & \multicolumn{3}{c}{ MBC $(\mu \mathrm{g} / \mathbf{m L})$} \\
\cline { 2 - 7 } & Ag NP (20 $\mathbf{~ m})$ & Ag NP (50 $\mathbf{~ m )}$ & Ag NW & Ag NP (20 nm) & Ag NP (50 nm) & Ag NW \\
\hline E. coli & 512 & 1024 & 128 & 1024 & 2048 & 512 \\
S. aureus & 256 & 512 & 32 & 512 & 1024 & 128 \\
\hline
\end{tabular}

To further investigate the antibacterial activities of the as-prepared nanocrystal products, we measured the growth curves of E. coli and S. aureus versus concentration, as shown in Figure 4. It was found that all of the silver nanocrystal products show high antibacterial activity, which was enhanced with the increase of the nanocrystal concentration. Additionally, the antimicrobial activity of silver nanoparticles was more effective against gram-positive bacteria $S$. aureus than that of the gram-negative bacteria $E$. coli. with the same concentration. The order of the as-prepared nanocrystal products by antibacterial activity is Ag NW, $20 \mathrm{~nm} \mathrm{Ag} \mathrm{NP}$, and $50 \mathrm{~nm} \mathrm{Ag} \mathrm{NP.} \mathrm{Compared} \mathrm{with} \mathrm{the} 50 \mathrm{~nm}$ $\mathrm{Ag} \mathrm{NP}$, the $20 \mathrm{~nm}$ size has a higher activity because it has a greater effective surface to load more silver ions [72]. Nevertheless, the Ag NW has the highest activity among the three nanocrystals, though it 
has the smallest effective surface, indicating that morphology plays a key role in the antibacterial activity of silver nanocrystals.
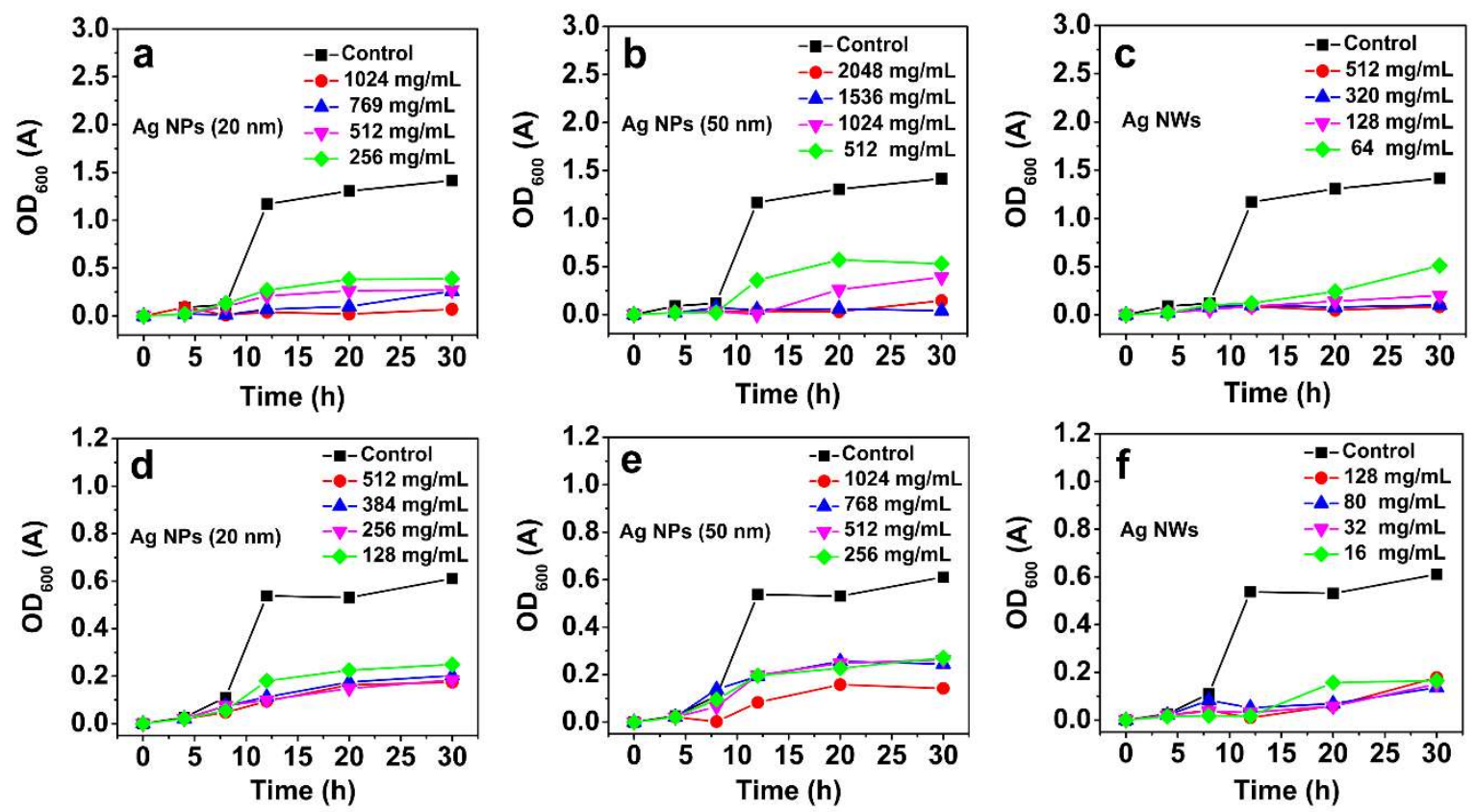

Figure 4. Growth curves of E. coli $(\mathbf{a}-\mathbf{c})$ and S. aureus $(\mathbf{d}-\mathbf{f})$ versus concentration.

\section{Conclusions}

We developed a reverse microemulsion method to fabricate Ag nanocrystals by incorporation of $\mathrm{H}_{2} \mathrm{O}$, n-heptane, and AOT. A variety of Ag nanocrystals with tunable sizes and morphologies were prepared and their antibacterial properties were investigated. As the molar ratio of water to surfactant is small, the resulted Ag nanocrystal products are sphere-like, and the antibacterial activity decreases as the size increases. As the molar ratio reached 25, the morphology of Ag nanocrystals evolved to be nanowire-like and exhibited a higher antibacterial activity than all of the sphere-like Ag nanocrystals. This work suggests that the morphology of silver nanocrystals plays a key role in the antibacterial process. Our method provides a simple, economic, and effective approach to preparing nanoparticles, which has promising applications in both material science and food industry.

Supplementary Materials: The following are available online at http:/ / www.mdpi.com/1996-1944/11/12/2498/ s1, Figure S1: Thermogravimetric analysis (TGA) of (a) pure surfactant AOT and (b) silver nanoparticle synthesized with the molar ratio of water to AOT $w=3$, Figure S2: UV-vis spectra of as-prepared silver nanoparticles synthesized with the molar ratio of water to AOT $w=3$ within $24 \mathrm{~h}$.

Author Contributions: Z.X. and Y.Y. supervised this project; A.F. conceived the idea and carried out the experiments with the help of J.C., J.W. and F.C.; A.F. and Y.Y. wrote the first version of the manuscript. All authors interpreted the experimental results and contributed to the revision of the manuscript.

Funding: This research was funded by the National Natural Science Foundation of China $(51576168,21503179)$ and Natural Science Foundation of Fujian Province (2016J05162).

Conflicts of Interest: The authors declare no conflicts of interest.

\section{Appendix A}

\section{Appendix A.1 MIC (Minimum Inhibitory Concentration)}

The antibacterial activity of a biomaterial is described in terms of MIC. In this work, MIC refers to the lowest concentration of the silver nanocrystal capable of inhibiting bacterium growth. Before the MIC measurement, the glassware and culture medium were sterilized (0.1 MPa steam, $121^{\circ} \mathrm{C}$, for $20 \mathrm{~min}$ ). A series of silver nanocrystal solutions with gradient concentrations were obtained 
by the double dilution method. Then $0.1 \mu \mathrm{L}$ of $10^{8}$ colony-forming units $(\mathrm{CFU}) / \mathrm{mL}$ bacteria suspension was added into each of the silver nanocrystal solutions. All the operations were conducted under sterile circumstances. Finally, the inoculated microdilution tubes were covered with silicone stoppers and incubated at $37^{\circ} \mathrm{C}$ for $24 \mathrm{~h}$ under shaking conditions. Evaluation of the MIC was then done by visual inspection of growth/no-growth in the mixtures containing different amounts of silver nanoparticle.

\section{Appendix A.2 MBC (Minimum Bactericidal Concentration)}

MBC is another parameter to describe the antibacterial activity of a biomaterial. In this work, it refers to the lowest concentration of the silver nanocrystal capable of killing the organism. After the MIC measurements, we continued to determine the MBC of our silver nanocrystals. To evaluate the $\mathrm{MBC}$, a $100 \mu \mathrm{L}$ solution without visible bacterium was removed from the tubes and coated onto agar plates. The plates were then incubated at $37^{\circ} \mathrm{C}$ for $24 \mathrm{~h}$. Then, evaluation of the MBC was done by a visual inspection when there is no surviving strain observed on the agar plates.

\section{Appendix A.3 Growth Curve}

Growth curve describes the growth of microorganisms, i.e., Escherichia coli and Staphylococcus aureus herein, with antibacterial agents. In this work, for each of the probe solutions, the growth curves were obtained by monitoring the evolution of optical density (OD) over $30 \mathrm{~h}$, which is performed by an ultraviolet-visible spectroscope with an incident light of $600 \mathrm{~nm}$ wavelength.

\section{References}

1. Fu, Y.; Yu, H.-Y.; Jiang, C.; Zhang, T.-H.; Zhan, R.; Li, X.; Li, J.-F.; Tian, J.-H.; Yang, R. NiCo alloy nanoparticles decorated on $\mathrm{N}$-doped carbon nanofibers as highly active and durable oxygen electrocatalyst. Adv. Funct. Mater. 2018, 28, 1705094. [CrossRef]

2. Li, C.; Yuan, Q.; Ni, B.; He, T.; Zhang, S.; Long, Y.; Gu, L.; Wang, X. Dendritic defect-rich palladium-copper-cobalt nanoalloys as robust multifunctional non-platinum electrocatalysts for fuel cells. Nat. Commun. 2018, 9, 3702. [CrossRef] [PubMed]

3. Kim, C.; Jeon, H.S.; Eom, T.; Jee, M.S.; Kim, H.; Friend, C.M.; Min, B.K.; Hwang, Y.J. Achieving selective and efficient electrocatalytic activity for $\mathrm{CO}_{2}$ reduction using immobilized silver nanoparticles. J. Am. Chem. Soc. 2015, 137, 13844-13850. [CrossRef]

4. He, L.; Weniger, F.; Neumann, H.; Beller, M. Synthesis, characterization, and application of metal nanoparticles supported on nitrogen-doped carbon: Catalysis beyond electrochemistry. Angew. Chem. Int. Ed. 2016, 55, 12582-12594. [CrossRef] [PubMed]

5. Tonga, G.Y.; Jeong, Y.; Duncan, B.; Mizuhara, T.; Mout, R.; Das, R.; Kim, S.T.; Yeh, Y.-C.; Yan, B.; Hou, S.; et al. Supramolecular regulation of bioorthogonal catalysis in cells using nanoparticle-embedded transition metal catalysts. Nat. Chem. 2015, 7, 597-603. [CrossRef] [PubMed]

6. Napruszewska, B.D.; Michalik, A.; Walczyk, A.; Duraczyńska, D.; Dula, R.; Rojek, W.; Lityńska-Dobrzyńska, L.; Bahranowski, K.; Serwicka, E.M. Composites of laponite and Cu-Mn hopcalite-related mixed oxides prepared from inverse microemulsions as catalysts for total oxidation of toluene. Materials 2018, 11, 1365. [CrossRef]

7. Cheng, L.; Ma, C.; Yang, G.; You, H.; Fang, J. Hierarchical silver mesoparticles with tunable surface topographies for highly sensitive surface-enhanced Raman spectroscopy. J. Mater. Chem. A 2014, 2, 4534-4542. [CrossRef]

8. Lee, J.-S.; Han, M.S.; Mirkin, C.A. Colorimetric detection of mercuric ion $\left(\mathrm{Hg}^{2+}\right)$ in aqueous media using DNA-functionalized gold nanoparticles. Angew. Chem. Int. Ed. 2007, 46, 4093-4096. [CrossRef]

9. Zhang, L.; Fang, M. Nanomaterials in pollution trace detection and environmental improvement. Nano Today 2010, 5, 128-142. [CrossRef]

10. Aragay, G.; Pons, J.; Merkoci, A. Recent trends in macro-, micro-, and nanomaterial-based tools and strategies for heavy-metal detection. Chem. Rev. 2011, 111, 3433-3458. [CrossRef]

11. Cecchini, M.P.; Turek, V.A.; Paget, J.; Kornyshev, A.A.; Edel, J.B. Self-assembled nanoparticle arrays for multiphase trace analyte detection. Nat. Mater. 2013, 12, 165-171. [CrossRef] [PubMed] 
12. Evanoff, D.D., Jr.; Chumanov, G. Size-controlled synthesis of nanoparticles. 1. "silver-only" aqueous suspensions via hydrogen reduction. J. Phys. Chem. B 2004, 108, 13948-13956. [CrossRef]

13. Heo, J.S.; Kim, K.-T.; Ban, S.-G.; Kim, Y.-J.; Kim, D.; Kim, T.; Hong, Y.; Kim, I.-S.; Park, S.K. Stable logic operation of fiber-based single-walled carbon nanotube transistor circuits toward thread-like CMOS circuitry. Materials 2018, 11, 1878. [CrossRef] [PubMed]

14. Sio, L.D.; Placido, T.; Comparelli, R.; Curri, M.L.; Striccoli, M.; Tabiryan, N.; Bunning, T.J. Next-generation thermo-plasmonic technologies and plasmonic nanoparticles in optoelectronics. Prog. Quant. Electron. 2015, 41, 23-70. [CrossRef]

15. Zacharatos, F.; Theodorakos, I.; Karvounis, P.; Tuohy, S.; Braz, N.; Melamed, S.; Kabla, A.; de la Vega, F.; Andritsos, K.; Hatziapostolou, A.; et al. Selective laser sintering of laser printed Ag nanoparticle micropatterns at high repetition rates. Materials 2018, 11, 2142. [CrossRef] [PubMed]

16. Ko, S.H. Low temperature thermal engineering of nanoparticle ink for flexible electronics applications. Semicond. Sci. Technol. 2016, 31, 073003. [CrossRef]

17. Bortolan, C.C.; Campanelli, L.C.; Bolfarini, C.; Oliveira, N.T.C. Fatigue strength of Ti-6Al-4V alloy with surface modified by $\mathrm{TiO}_{2}$ nanotubes formation. Mater. Lett. 2016, 177, 46-49. [CrossRef]

18. Mukheem, A.; Muthoosamy, K.; Manickam, S.; Sudesh, K.; Shahabuddin, S.; Saidur, R.; Akbar, N.; Sridewi, N. Fabrication and characterization of an electrospun PHA/graphene silver nanocomposite scaffold for antibacterial applications. Materials 2018, 11, 1673. [CrossRef]

19. Gopinathan, P.; Ashok, A.M.; Selvakumar, R. Bacterial flagella as biotemplate for the synthesis of silver nanoparticle impregnated bionanomaterial. Appl. Surf. Sci. 2013, 276, 717-722. [CrossRef]

20. Park, J.S.; Yang, H.N.; Yi, S.W.; Kim, J.-H.; Park, K.-H. Neoangiogenesis of human mesenchymal stem cells transfected with peptide-loaded and gene-coated PLGA nanoparticles. Biomaterials 2016, 76, $226-237$. [CrossRef]

21. Jabłońska-Stencel, E.; Pakieła, W.; Mertas, A.; Bobela, A.; Kasperski, J.; Chladek, G. Effect of silver-emitting filler on antimicrobial and mechanical properties of soft denture lining material. Materials 2018, 11, 318. [CrossRef] [PubMed]

22. Wang, J.; Li, J.; Guo, G.; Wang, Q.; Tang, J.; Zhao, Y.; Qin, H.; Wahafu, T.; Shen, H.; Liu, X.; et al. Silver-nanoparticles-modified biomaterial surface resistant to staphylococcus: New insight into the antimicrobial action of silver. Sci. Rep. 2016, 6, 32699. [CrossRef]

23. Shahverdi, A.R.; Fakhimi, A.; Shahverdi, H.R.; Minaian, S. Synthesis and effect of silver nanoparticles on the antibacterial activity of different antibiotics against Staphylococcus aureus and Escherichia coli. Nanomed. Nanotechnol. Biol. Med. 2007, 3, 168-171. [CrossRef] [PubMed]

24. Raza, M.A.; Kanwal, Z.; Rauf, A.; Sabri, A.N.; Riaz, S.; Naseem, S. Size- and shape-dependent antibacterial studies of silver nanoparticles synthesized by wet chemical routes. Nanomaterials 2016, 6, 74. [CrossRef]

25. Porcaro, F.; Carlini, L.; Ugolini, A.; Visaggio, D.; Visca, P.; Fratoddi, I.; Venditti, I.; Meneghini, C.; Simonelli, L.; Marini, C.; et al. Synthesis and structural characterization of silver nanoparticles stabilized with 3-mercapto-1-propansulfonate and 1-thioglucose mixed thiols for antibacterial applications. Materials 2016, 9, 1028. [CrossRef]

26. Lara, H.H.; Garza-Treviño, E.N.; Ixtepan-Turrent, L.; Singh, D.K. Silver nanoparticles are broad-spectrum bactericidal and virucidal compounds. J. Nanobiotechnol. 2011, 9, 30. [CrossRef]

27. Yu, L.; Zhang, Y.; Zhang, B.; Liu, J. Enhanced antibacterial activity of silver nanoparticles/halloysite nanotubes/graphene nanocomposites with sandwich-like structure. Sci. Rep. 2014, 4, 4551. [CrossRef]

28. Shi, Z.; Tang, J.; Chen, L.; Yan, C.; Tanvir, S.; Anderson, W.A.; Berry, R.M.; Tam, K.C. Enhanced colloidal stability and antibacterial performance of silver nanoparticles/cellulose nanocrystal hybrids. J. Mater. Chem. B 2015, 3, 603-611. [CrossRef]

29. Besinis, A.; Hadi, S.D.; Le, H.R.; Tredwin, C.; Handy, R.D. Antibacterial activity and biofilm inhibition by surface modified titanium alloy medical implants following application of silver, titanium dioxide and hydroxyapatite nanocoatings. Nanotoxicology 2017, 11, 327-338. [CrossRef] 
30. Jha, D.; Thiruveedula, P.K.; Pathak, R.; Kumar, B.; Gautam, H.K.; Agnihotri, S.; Sharma, A.K.; Kumar, P. Multifunctional biosynthesized silver nanoparticles exhibiting excellent antimicrobial potential against multi-drug resistant microbes along with remarkable anticancerous properties. Mater. Sci. Eng. C 2017, 80, 659-669. [CrossRef]

31. Liu, L.; Cai, R.; Wang, Y.; Tao, G.; Ai, L.; Wang, P.; Yang, M.; Zuo, H.; Zhao, P.; Shen, H.; et al. Preparation and characterization of AgNPs in situ synthesis on polyelectrolyte membrane coated sericin/agar film for antimicrobial applications. Materials 2018, 11, 1205. [CrossRef] [PubMed]

32. Ni, X.; Wang, J.; Yue, Y.; Cheng, W.; Wang, D.; Han, G. Enhanced antibacterial performance and cytocompatibility of silver nanoparticles stabilized by cellulose nanocrystal grafted with chito-oligosaccharides. Materials 2018, 11, 1339. [CrossRef] [PubMed]

33. Ip, M.; Lui, S.L.; Poon, V.K.M.; Lung, I.; Burd, A. Antimicrobial activities of silver dressings: An in vitro comparison. J. Med. Microbiol. 2006, 55, 59-63. [CrossRef] [PubMed]

34. Lee, H.Y.; Park, H.K.; Lee, Y.M.; Kim, K.; Park, S.B. A practical procedure for producing silver nanocoated fabric and its antibacterial evaluation for biomedical applications. Chem. Commun. 2007, 28, 2959-2961. [CrossRef] [PubMed]

35. Hazer, D.B.; Mut, M.; Dincer, N.; Saribas, Z.; Hazer, B.; Özgen, T. The efficacy of silver-embedded polypropylene-grafted polyethylene glycol-coated ventricular catheters on prevention of shunt catheter infection in rats. Childs Nerv. Syst. 2012, 28, 839-846. [CrossRef]

36. Spielman-Sun, E.; Zaikova, T.; Dankovich, T.; Yun, J.; Ryan, M.; Hutchison, J.E.; Lowry, G.V. Effect of silver concentration and chemical transformations on release and antibacterial efficacy in silver-containing textiles. NanoImpact 2018, 11, 51-57. [CrossRef]

37. Juknius, T.; Ružauskas, M.; Tamulevičius, T.; Šiugždinienè, R.; Jukniene, I.; Vasiliauskas, A.; Jurkevičiūtė, A.; Tamulevičius, S. Antimicrobial properties of diamond-like carbon/silver nanocomposite thin films deposited on textiles: Towards smart bandages. Materials 2016, 9, 371. [CrossRef]

38. Actis, L.; Srinivasan, A.; Lopez-Ribot, J.L.; Ramasubramanian, A.K.; Ong, J.L. Effect of silver nanoparticle geometry on methicillin susceptible and resistant Staphylococcus aureus, and osteoblast viability. J. Mater. Sci. Mater. Med. 2015, 26, 215. [CrossRef]

39. Stefaniak, A.B.; Duling, M.G.; Lawrence, R.B.; Thomas, T.A.; LeBouf, R.F.; Wade, E.E.; Virji, M.A. Dermal exposure potential from textiles that contain silver nanoparticles. Int. J. Occup. Environ. Health 2014, 20, 220-234. [CrossRef]

40. Cushen, M.; Kerry, J.; Morris, M.; Cruz-Romero, M.; Cummins, E. Evaluation and simulation of silver and copper nanoparticle migration from polyethylene nanocomposites to food and an associated exposure assessment. J. Agric. Food Chem. 2014, 62, 1403-1411. [CrossRef]

41. Echegoyen, Y.; Nerín, C. Nanoparticle release from nano-silver antimicrobial food containers. Food Chem. Toxicol. 2013, 62, 16-22. [CrossRef]

42. Kanmani, P.; Lim, S.T. Synthesis and structural characterization of silver nanoparticles using bacterial exopolysaccharide and its antimicrobial activity against food and multidrug resistant pathogens. Process Biochem. 2013, 48, 1099-1106. [CrossRef]

43. Cheng, Q.; Yang, L.; Zou, L.; Zou, Z.; Chen, C.; Hu, Z.; Yang, H. Single cobalt atom and N codoped carbon nanofibers as highly durable electrocatalyst for oxygen reduction reaction. ACS Catal. 2017, 7, 6864-6871. [CrossRef]

44. Leopold, N.; Lendl, B. A new method for fast preparation of highly surface-enhanced raman scattering (SERS) active silver colloids at room temperature by reduction of silver nitrate with hydroxylamine hydrochloride. J. Phys. Chem. B 2003, 107, 5723-5727. [CrossRef]

45. Zhu, W.; Wu, Y.; Yan, C.; Wang, C.; Zhang, M.; Wu, Z. Facile synthesis of mono-dispersed polystyrene (PS)/Ag composite microspheres via modified chemical reduction. Materials 2013, 6, 5625-5638. [CrossRef]

46. Zhang, Q.; Li, N.; Goebl, J.; Lu, Z.; Yin, Y. A systematic study of the synthesis of silver nanoplates: Is citrate a "magic" reagent? J. Am. Chem. Soc. 2011, 133, 18931-18939. [CrossRef]

47. Wang, Y.; Liu, W.; Liu, W.; He, P.; Fan, Z.; Wang, X.; Yu, D.; Guo, J.; Guo, B.; Shen, H. Synthesis of SnAgCu nanoparticles with low melting point by the chemical reduction method. Microelectron. Reliab. 2017, 78, 17-24. [CrossRef]

48. Sotiriou, G.A.; Pratsinis, S.E. Antibacterial activity of nanosilver ions and particles. Environ. Sci. Technol. 2010, 44, 5649-5654. [CrossRef] 
49. Zhang, J.-P.; Chen, P.; Sun, C.-H.; Hu, X.-J. Sonochemical synthesis of colloidal silver catalysts for reduction of complexing silver in DTR system. Appl. Catal. A Gen. 2004, 266, 49-54. [CrossRef]

50. Chen, A.; Ma, S.; Zhuo, Y.; Chai, Y.; Yuan, R. In situ electrochemical generation of electrochemiluminescent silver naonoclusters on target-cycling synchronized rolling circle amplification platform for microRNA detection. Anal. Chem. 2016, 88, 3203-3210. [CrossRef]

51. Singh, P.; Carpenter, R.W.; Buttry, D.A. Electrochemical cycling of polycrystalline silver nanoparticles produces single-crystal silver nanocrystals. Langmuir 2017, 33, 13490-13495. [CrossRef] [PubMed]

52. Mamme, M.H.; Cherigui, E.A.M.; Dolgikh, O.; Ustarroz, J.; Simillion, H.; Terryn, H.; Deconinck, J. A finite element simulation of the electrochemical growth of a single hemispherical silver nucleus. Electrochim. Acta 2016, 197, 307-317. [CrossRef]

53. Nasretdinova, G.R.; Fazleeva, R.R.; Mukhitova, R.K.; Nizameev, I.R.; Kadirov, M.K.; Ziganshina, A.Y.; Yanilkin, V.V. Electrochemical synthesis of silver nanoparticles in solution. Electrochem. Commun. 2015, 50, 69-72. [CrossRef]

54. Mandal, S.; Rautaray, D.; Sastry, M. $\mathrm{Ag}^{+}-$Keggin ion colloidal particles as novel templates for the growth of silver nanoparticle assemblies. J. Mater. Chem. 2003, 13, 3002-3005. [CrossRef]

55. Kim, H.-J.; Shin, J.-G.; Park, C.-S.; Kum, D.S.; Shin, B.J.; Kim, J.Y.; Park, H.-D.; Choi, M.; Tae, H.-S. In-liquid plasma process for size- and shape-controlled synthesis of silver nanoparticles by controlling gas bubbles in water. Materials 2018, 11, 891. [CrossRef] [PubMed]

56. Zhou, Q.F.; Xu, Z. The preparation of nano-scale plate silver powders by visible light induction method. J. Mater. Sci. 2004, 39, 2487-2491. [CrossRef]

57. Gabriel, J.S.; Gonzaga, V.A.M.; Poli, A.L.; Schmitt, C.C. Photochemical synthesis of silver nanoparticles on chitosans/montmorillonite nanocomposite films and antibacterial activity. Carbohydr. Polym. 2017, 171, 202-210. [CrossRef]

58. dos Santos, P.L.; Katic, V.; Toledo, K.C.F.; Bonacin, J.A. Photochemical one-pot synthesis of reduced graphene oxide/Prussian blue nanocomposite for simultaneous electrochemical detection of ascorbic acid, dopamine, and uric acid. Sens. Actuat. B-Chem. 2018, 255, 2437-2447. [CrossRef]

59. Wang, Y.-H.; Hong, Z.-W.; Sun, Y.-Y.; Li, D.-F.; Han, D.; Zheng, J.-F.; Niu, Z.-J.; Zhou, X.-S. Tunneling decay constant of alkanedicarboxylic acids: Different dependence on the metal electrodes between air and electrochemistry. J. Phys. Chem. C 2014, 118, 18756-18761. [CrossRef]

60. Oluwafemi, O.S.; Mochochoko, T.; Leo, A.J.; Mohan, S.; Jumbam, D.N.; Songca, S.P. Microwave irradiation synthesis of silver nanoparticles using cellulose from Eichhornia crassipes plant shoot. Mater. Lett. 2016, 185, 576-579. [CrossRef]

61. Naik, R.R.; Stringer, S.J.; Agarwal, G.; Jones, S.E.; Stone, M.O. Biomimetic synthesis and patterning of silver nanoparticles. Nat. Mater. 2002, 1, 169-172. [CrossRef] [PubMed]

62. Kowshik, M.; Ashtaputre, S.; Kharrazi, S.; Vogel, W.; Urban, J.; Kulkarni, S.K.; Paknikar, K.M. Extracellular synthesis of silver nanoparticles by a silver-tolerant yeast strain MKY3. Nanotechnology 2003, 14, 95-100. [CrossRef]

63. Das, V.L.; Thomas, R.; Varghese, R.T.; Soniya, E.V.; Mathew, J.; Radhakrishnan, E.K. Extracellular synthesis of silver nanoparticles by the Bacillus strain CS 11 isolated from industrialized area. 3 Biotech 2014, 4, 121-126. [CrossRef] [PubMed]

64. Husen, A.; Siddiqi, K.S. Phytosynthesis of nanoparticles: Concept, controversy and application. Nanoscale Res. Lett. 2014, 9, 229. [CrossRef]

65. Priyadarshini, S.; Gopinath, V.; Priyadharsshini, N.M.; MubarakAli, D.; Velusamy, P. Synthesis of anisotropic silver nanoparticles using novel strain, Bacillus flexus and its biomedical application. Colloids Surf. B 2013, 102, 232-237. [CrossRef]

66. Politi, M.J.; Brandt, O.; Fendler, J.H. Ground- and excited-state proton transfers in reversed micelles. Polarity restrictions and isotope effects. J. Phys. Chem. 1985, 89, 2345-2354. [CrossRef]

67. Lisiecki, I.; Pileni, M.P. Copper metallic particles synthesized "in situ" in reverse micelles: Influence of various parameters on the size of the particles. J. Phys. Chem. 1995, 99, 5077-5082. [CrossRef]

68. Murphy, C.J.; Jana, N.R. Controlling the aspect ratio of inorganic nanorods and nanowires. Adv. Mater. 2002, 14, 80-82. [CrossRef]

69. Jiang, D.; Deng, Y.; Gao, G.; Wu, L.; Yang, H. Self-assembly of silica nanowires in a microemulsion system and their adsorption capacity. Colloids Surf. A 2018, 538, 526-533. [CrossRef] 
70. Zhang, W.; Qiao, X.; Chen, J. Synthesis of silver nanoparticles-Effects of concerned parameters in water/oil microemulsion. Mater. Sci. Eng. B 2007, 142, 1-15. [CrossRef]

71. Zheng, X.; Zhu, L.; Yan, A.; Wang, X.; Xie, Y. Controlling synthesis of silver nanowires and dendrites in mixed surfactant solutions. J. Colloid Interf. Sci. 2003, 268, 357-361. [CrossRef]

72. Reidy, B.; Haase, A.; Luch, A.; Dawson, K.A.; Lynch, I. Mechanisms of silver nanoparticle release, transformation and toxicity: A critical review of current knowledge and recommendations for future studies and applications. Materials 2013, 6, 2295-2350. [CrossRef] [PubMed]

(C) 2018 by the authors. Licensee MDPI, Basel, Switzerland. This article is an open access article distributed under the terms and conditions of the Creative Commons Attribution (CC BY) license (http:/ / creativecommons.org/licenses/by/4.0/). 